\title{
Misconceptions on ATP thermodynamic role in cellular processes
}

\author{
Martins, R. M.; Torres, B. B. \\ Departamento de Bioquímica, IQ, USP, SP, Brazil
}

The occurrence and permanence of misconceptions have negative implications on the learning processes since it impairs the construction of significant learning. Misconceptions correction is a complex task due to the difficulties in their detection and high resistance to their removal. The main objective of the present work was to investigate misconceptions about the thermodynamic role of the ATP in cellular processes. Tests were realized with high school (HS), undergraduate (UG) and graduate students involved in $\mathrm{PhD}$ programs $(\mathrm{G})$. In this survey students answered a 15 item questionnaire dealing with the ATP role as the cellular energy source. The stability of such misconceptions were verified: one result shows that $68 \% \mathrm{HS}, 92 \% \mathrm{UG}$ and $91 \%$ $G$ students state that the energy from ATP hydrolysis is responsible for driving cellular processes. Overall results show that students carry misconceptions on basic thermodynamic concepts such as energy transfer and chemical reactions spontaneity. One source of the prevalence of the discussed misconceptions are textbooks, where schemes, figures and even text early introduce false concepts on the ATP role.

Keywords: misconceptions, ATP thermodynamics, cellular energy source Supported by: CNPq 
This document was created with Win2PDF available at http://www.win2pdf.com. The unregistered version of Win2PDF is for evaluation or non-commercial use only. This page will not be added after purchasing Win2PDF. 